$\mathrm{NaCl}$ and $\mathrm{LiCl}$ under these conditions before the simultaneous discrimination test was run. It may be that, by Day 20 , the rats were trained not to drink rather than perform a difficult discrimination. The use of separate test and home cages would be expected to favor the development of a "nondrinking" discrimination.

There are several implications of the present work. First, the performance of a discriminative response depends upon both the presence of cues and appropriate $r e$ inforcement contingencies. Discrimination paradigms must be examined carefully to be certain that a failure of a discriminative response to appear can be attributed to the absence of cues rather than to the reinforcement contingencies. Second, the avoidance of $\mathrm{NaCl}$ solutions after experience with $\mathrm{LiCl}$ solutions could be due to failure of discrimination or to generalization of the avoidance behavior. It would appear that the second interpretation is more likely.

\section{REFERENCES}

BEIDLER, L. M. Properties of the chemoreceptors of the tongue of the rat. Journal of Neurophysiology, 1953, 16, 595-607.

COWEY, A. Discrimination. In L. Weiskrantz (Ed.) Analysis of behavioral change. New York: Harper \& Row, 1968. Pp. 189-238.

FISHMAN, I. Y. Single fiber gustatory impulses in the rat and hamster. Journal of Comparative Physiology, 1957, 49, 319-334.

GARCIA, J., \& KOELLING, R. A. Relation of cue to consequence in avoidance learning. Psychonomic Science, 1966, 4, 123-124.

NACHMAN, M. Learned aversion to the taste of lithium chloride and generalization to other salts. Journal of Comparative \& Physiological Psychology, 1963, 56, 343-349.

$$
\text { NOTES }
$$

1. These studies were executed in an experimental psychology laboratory taught by the third author and were subjected to two independent replications. Thanks are due to Dr. James Voss, Department Chairman, for agreeing that "real experiments" could be done in a teaching/learning situation.

2. Send reprint requests to J.F. Brody, Department of Psychiatry, Yale University Medical School, 34 Park St., New Haven, Conn. 06508 .

\title{
Number of training trials and frustration effects of nonzero reward reduction in the double alley
}

RICHARD L. PATTEN and DAVID B. MYERS, Iowa State University, Ames, IOWa 50010

$A$ double runway was employed to examine the possibility that nonzero reduction of reward in the first goalbox (BI) leads to frustration effects in the form of energized running in the second runway. Groups of rats were given 12 or 72 rewarded runs to eight pellets in $B 1$ prior to receiving a test phase of 24 trials, which included 12 trials on which a single BI pellet was available. Significant interactions between number of preshift rewards and FE magnitude in both start - and run-speed measures provided evidence for frustration effects of nonzero reward reduction.

According to the Amsel (1958)-Spence (1960) frustration theory, nonreward (F trial) of a previously rewarded response produces a frustrative increment in an organism's drive level. In the familiar supported this assumption by showing that the difference between $A 2$ running speeds on B1 reward and B1 nonreward trials (designated FE) is greater in Ss having 60 prior B1 rewards than in Ss having 12 B1 rewards.

Although part of the FE may be due to hunger differences on B1 reward and Bl nonreward trials, the Yelen (1969) results point to involvement of a conditioning factor in producing the FE. The present experiment-similar in design to the Yelen (1969) study-provided the same sort of support for a frustration interpretation of $\mathrm{FE}$ produced by nonzero $B 1$ reward reduction.

\section{METHOD}

The Ss were 24 naive male hooded rats, 110-120 days old at the start of the experiment.

The apparatus was a flat-black L-shaped double runway, $4 \frac{13}{2} \mathrm{in}$. high and $3 \frac{3}{4} \mathrm{in}$. wide throughout. A 13-in. startbox led into $A 1$, which was 60 in. long and terminated in a 16-in. goalbox. The 8-in. right-angled foot of B1 led to the A2 start-door. A2 was 76 in. long. Startbox, runway, and goalbox sections of the apparatus were defined by opaque sliding doors. Metal measuring spoons, $1 \mathrm{in}$. in diam, protruded from the end of $\mathrm{B} 1$ and $\mathrm{A} 21 / \mathrm{1} / \mathrm{in}$. above the floor and served as foodcups. A small 6.3.V ac lamp over the foodcup illuminated B1. The apparatus was illuminated by dim, diffuse fluorescent room lighting. Ss were permitted entry into $\mathrm{A} 2$ within a minimum of $13 \mathrm{sec}$ after eating in $\mathrm{B} 1$, which included $10 \mathrm{sec}$ plus $3 \mathrm{sec}$ orientation toward the A2 door. This procedure was designed to approximate the 15 -sec value that appears to be optimal for FE (MacKinnon \& Amsel, 1964).

When the start-door to A2 was opened, an electronic clock started. Sequential interruption of photobeams 2 in. and 14 in. from the A2 start-door operated electronic clocks, providing start and run time measures over 2-in. and 12-in. segments of $\mathrm{A} 2$.

Two weeks prior to the start of experimental training, Ss were placed on a diet of $10 \mathrm{~g} /$ day of lab chow until each S's weight dropped to $77 \%$ of his preexperimental weight. Twenty-four Ss were assigned randomly to two experimental groups, which received 12 (Group 12) or 72 (Group 72) rewarded training trials at the rate of four trials/day. All Ss received eight .045 -g Noyes pellets in B1 and three pellets at the end of $A 2$. After the preshift training, Ss were shifted to a $50 \%$ schedule of $\mathrm{B} 1$ reward reduction for 24 trials. During the reduction phase, half of each day's trials were to eight B1 pellets and half were to one B1 pellet according to the following six four-trial 


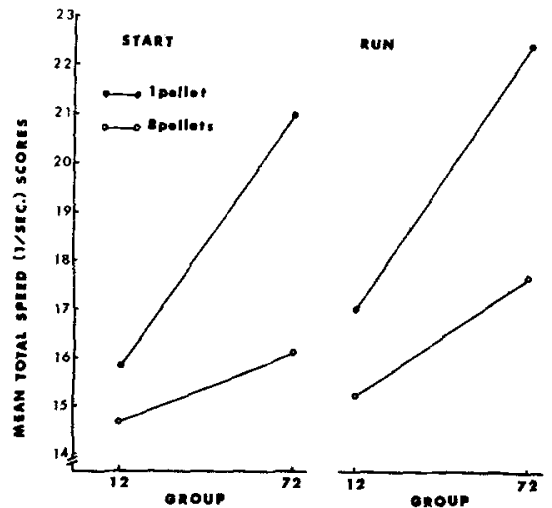

Fig. 1. Alley 2 start and run speeds on nonreduction (eight pellets) and reduction (one pellet) trials for Group 12 and Group 72.

sequences: $8181,1881,8118,1188,1818$, 8811 . Each $\mathrm{S}$ was assigned randomly one of the above four-trial sequences to start the reduction phase. At the end of reduction-phase trials, each $S$ had experienced all of the four-trial sequences.

Possible differential effects due to handling, deprivation, and age in the two groups were controlled by putting all Ss on deprivation at the same time, but giving Group 12 Ss 60 trials of placement for $30 \mathrm{sec}$ onto a pan containing sawdust while Group 72 Ss got their first 60 rewarded training trials. Ss from both groups began reduction-phase trials on the same day.
RESULTS AND DISCUSSION

Individual latency measures taken during reduction-phase triais were converted to reciprocals, and analysis of variance was applied to the reduction-trial total and nonreduction-trial total scores of each $S$.

Figure 1 presents mean start and run speeds on reduction and nonreduction trials for the two experimental groups.

Specifically, the frustration theory prediction was for a significant interaction between $N_{G}$ groups and $F E$ magnitude, with Group 72 having the larger FE. This prediction was confirmed in both start and run measures, with $\mathrm{F}(1,20)=4.78, \mathrm{p}<.05$ and $F(1,20)=4.40, p<.05$, respectively. Using a critical value of $F(1,20)=4.35$, $\mathrm{p}<.05$ for simple-effect comparisons, the Group 72 FE was significant in both start and run measures. Both FE comparisons were statistically nonsignificant in Group 12.

Although the present data and the Yelen (1969) data implicate a conditioning factor in the production of $\mathrm{FE}$, it must be considered that part of this factor may be A2 running habit $(\mathrm{H})$ rather than conditioned incentive $\left(I_{g}\right)$ to $B 1$ cues. Thus, the present results may be derived given the following: a difference in A2 running habit $(\mathrm{H})$ between Group 72 and Group $12 \mathrm{Ss}$, equally strong reduction-trial drive (D) from hunger and/or frustration in both groups, and a multiplicative relation between $\mathrm{H}$ and $\mathrm{D}$.

Differential A2 running habit between the two groups would produce faster A2 running on nonreduction trials by Group 72 Ss than by Group 12 Ss. However, the nonreduction-trial start and run speed differences between the two groups were not large enough to attain statistical significance. Thus, the data of the present study are taken as implicating a factor of conditioned incentive $\left(r_{g}\right)$ in producing the $\mathrm{FE}$, and as providing support for the applicability of frustration theory to the effects of nonzero reward reduction.

\section{REFERENCES}

AMSEL, A. The role of frustrative nonreward in noncontinuous reward situations. Psychological Bulletin, 1958, 55, 102-119.

BARRETT, R., PEYSER, C. S., \& McHOSE, J. Effects of complete and incomplete reward reduction on a subsequent response. Psychonomic Science, 1965, 3, 277-278.

BOWER, G. H. The influence of graded reductions in reward and prior frustrating events upon the magnitude of the frustration effect. Journal of Comparative \& Physiological Psychology, 1962, 55, 582-587.

MacKINNON, J. R., \& AMSEL, A. Magnitude of the frustration effect as a function of confinement and detention in the frustrating situation. Journal of Experimental Psychology, $1964,67,468-474$.

SPENCE, K. W. Behavior theory and learning. Englewood Cliffs, N.J: Prentice-Hall, 1960.

WAGNER, A. R. The role of reinforcement and nonreinforcement in an "apparent frustration effect." Joumal of Experimental Psychology, 1959, 57, 130-136.

YELEN, D. Magnitude of the frustration effect and number of training trials. Psychonomic Science, 1969, 15, 137-138. 